\title{
Digital cholangioscopy: assessing the impact of radiofrequency ablation
}

Radiofrequency ablation (RFA) has been shown to be an efficacious therapy that improves survival in patients with malignant biliary strictures [1]. Direct cholangioscopy can be useful in confirming a successful response to therapy. We present the case of a patient who underwent RFA of a distal malignant biliary stricture, with cholangioscopic images obtained before and after the procedure confirming successful ablation.

A 66-year-old woman with an inoperable malignant biliary stricture presented for endoscopic retrograde cholangiopancreatography (ERCP). The duodenoscope (TGFQ180V; Olympus America, Center Valley, Pennsylvania, USA) was advanced to the ampulla. An occlusion cholangiogram showed a dilated biliary tree above a distal biliary stricture. A digital cholangioscope (SpyGlass; Boston Scientific, Natick, Massachusetts, USA) was inserted into the bile duct, and the stricture was visualized. Oozing, erythematous mucosa consistent with malignancy was seen in the distal portion of the duct.

An RFA catheter (Habib EndoHPB; EMcision, Montreal, Canada) was advanced into the stricture, and RFA was performed at 8 effect and $10 \mathrm{~W}$ for 90 seconds [2]. The cholangioscope was then reinserted, and visualization showed successfully ablated tissue with localized necrosis ( $\bullet$ Fig. 1, Video 1). Finally, a metal stent (WallFlex; Boston Scientific) was deployed.

New applications for cholangioscopy are emerging as a consequence of the incorporation of a new digital cholangioscopy system into the endoscopic arsenal. One such application is to confirm successful ablation in malignant strictures after RFA. This case illustrates the impressive necrosis that RFA induces when used as a palliative therapy in patients with malignant biliary strictures.

Endoscopy_UCTN_Code_TTT_1AR_2AF
Competing interests: Michel Kahaleh MD: has received grant support from Boston Scientific, Fujinon, EMcison, Xlumena Inc., W.L. Gore, MaunaKea, Apollo Endosurgery, Cook Endoscopy, ASPIRE Bariatrics, GI Dynamics, NinePoint Medical, Merit Medical and MI Tech. He is a consultant for Boston Scientific, Xlumena Inc., Concordia Laboratories Inc. and MaunaKea Tech.

\section{Amy Tyberg, Steven Zerbo, Reem Z. Sharaiha, Michel Kahaleh}

Division of Gastroenterology \& Hepatology, Weill Cornell Medical College, Cornell University, New York, New York, USA

\section{References}

1 Sharaiha RZ, Sethi A, Weaver KR et al. Impact of radiofrequency ablation on malignant biliary strictures: results of a collaborative registry. Dig Dis Sci 2015; 60: 2164-2169

2 Figueroa-Barojas P, Bakhru MR, Habib NA et al. Safety and efficacy of radiofrequency ablation in the management of unresectable bile duct and pancreatic cancer: a novel palliation technique. J Oncol 2013; 2013: 910897

\section{Bibliography}

Dol http://dx.doi.org/

10.1055/s-0034-1393144

Endoscopy 2015; 47: E544

(c) Georg Thieme Verlag KG

Stuttgart · New York

ISSN 0013-726X

\section{Corresponding author}

\section{Michel Kahaleh, MD, FASGE}

Division of Gastroenterology and Hepatology

Weill Cornell Medical College

1305 York Avenue, 4th Floor

New York, NY 10021

USA

Fax: +1-646-962-0110

mkahaleh@gmail.com

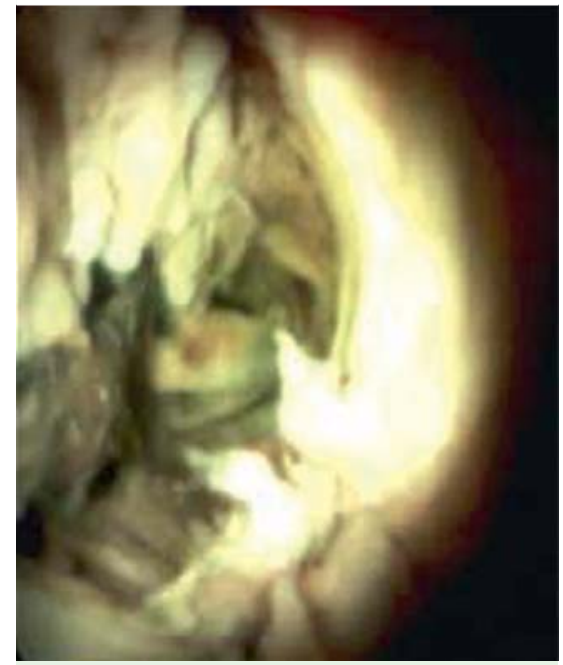

Fig. 1 Cholangioscopic image of intense intraductal necrosis induced by radiofrequency ablation.

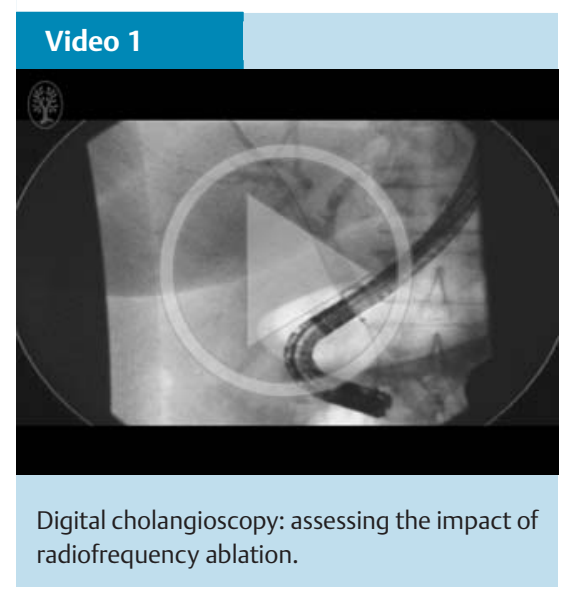

